\begin{tabular}{c|l}
$\Delta=$\begin{tabular}{l|l}
36,1 \\
28,6
\end{tabular} & Rh. F. Juli 1827 \\
21,2 & August \\
20,6 & September \\
24,3 & October \\
31,9 & November \\
22,0 & December \\
4,6 & Januar 1828 \\
14,2 & Februar \\
21,1 & März \\
37,2 & April \\
26,5 & Mai \\
25,6 & Juni \\
22,1 & Juli \\
31,7 & August \\
28,6 & September \\
12,1 & October \\
25,4 & November
\end{tabular}

Aus allen im Jahre 1827 angestellten Beobachtungen ist $\Delta=28,5$, aus den Beobachtungen der 9 letzten Monate $\Delta=27,2$, wefshalb ich, ehe ein Nivellement die Erhebung des Danziger Barometers ausgemittelt hatte, aus der bekannten Erhebung des Königsberger Barometers von 70,4 Rheinl. Furs geschlossen hatte, das Danziger Barometer stehe 43 Rh. F. über der Ostsee. Durch Hinzuziehung der drei ersten Monate des J. 1827 erhält man $\Delta=28,5 \mathrm{~F}$. aus den Beobachtungen des J. $1828 \Delta=22,6$

Aus allen 684 Beobachtungen der J. 1827 u. 1828 folgt

$$
\begin{aligned}
& \Delta=25,6 \mathrm{Rh} . \mathrm{F} \text {. } \\
& \text { aus dem Nivellement } \Delta=24,2 \text {. }
\end{aligned}
$$

\title{
Strehlke.
}

\section{Osservazioni di Vesta intorno all' opposizione col Sole fatte nell' I. R. Osservatorio di Padora.}

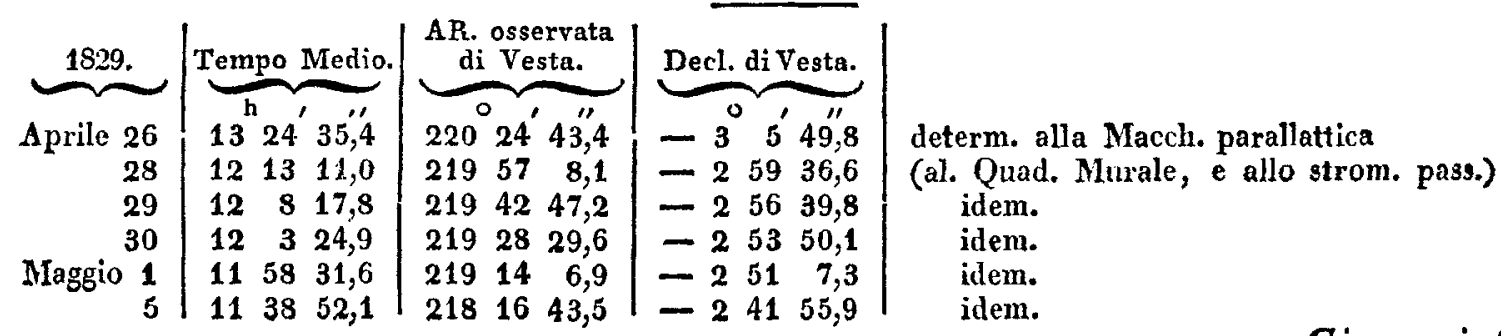

\section{Giovanni Santini.}

Schreiben des Herrn George Innes aus Aberdeen an den Herausgeher. Aberdeen 1829. April 18.

Having had early communications of the observations of the Solar Eclipse of the 29th November 1826, which were made in Great Britain and Ireland, I made the necessary calculations, in order to deduce the longitude of each of the places where the observations were made, and communicated the results to the Astronomical Society of London, which the commitlee of the Society published in their monthly notices, in the Philosophical Magazine and Annals of Philosophy for September 1827. - In addition to the Observations made in this country, $I$ have lalely met with some others, made in Germany and Italy; and although most of these have been already calculated by M. Wurm and M. Santini, and inserted in some of the numbers of the Astronomische Nachrichten, they could not be compared with those I had previously calculated, as it appears that M. Santini used Carlini's 'Tables of the Sun, and Burckhardt's Tables of the Moon; whereas I used Delambre's Solar, and Damoiseau's Lunar Tables; and M. Wurm does not state what set of tables he has used. Also, the ellipticity, $\frac{T}{509}$, which I have used for reducing the Latitudes of the places of observation, and also the Moon's parallax, differs from that used by Mr. Santini, which is $\frac{1}{330}$. It does not appear what ellipticity M. Wurm has used. Although the figure of the earth has not as yet been satisfactorily ascertained, I do not think it can very much affect the present results, where the same ellipticity has been used for each place of observation. Whatever ay have been the ellipticity used by M. Wurm, his difference of longitude of Bushey Heath and Aberdeen, differs only 0 " 03 from mine, but the difference of our results for $\mathrm{Abo}$, is considerable. No correction was applied to the semidiameter of the Sun for Irradiation, nor to that of the Moon for Inflexion as these have not been well ascertained by Astronomers.

Having reason to think the Bushey Heath observations as good as most of the others, as its longitude has been well ascertained, and as both the beginning and end of the eclipse were observed, I have used it as the basis in the reductions. It is in Longitude $10^{\prime} 42^{\prime \prime}, 43$, in time, West from Paris. 


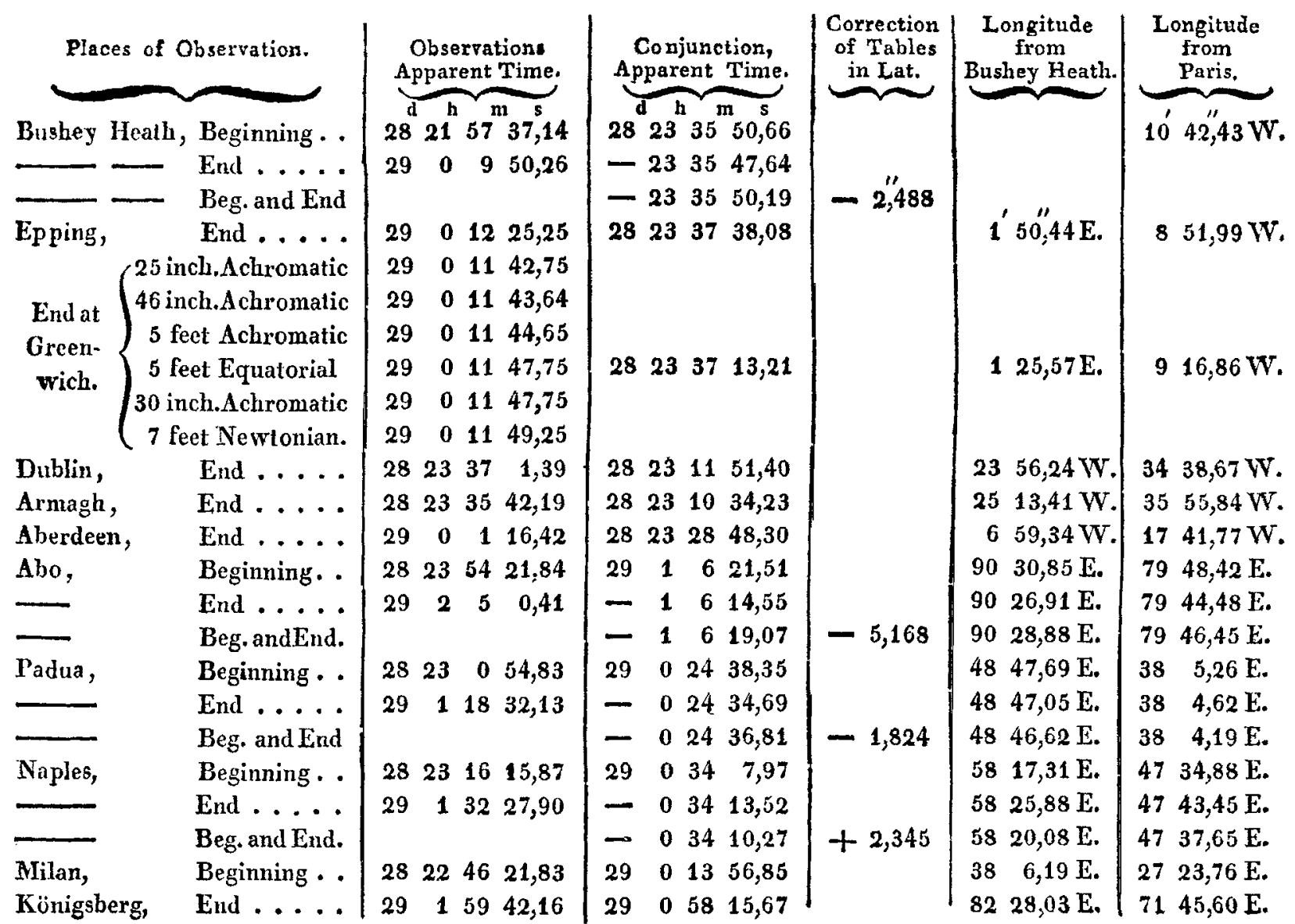

There appears to be some error in the Naples observations, as the error of the Tables in Latitude comes out with a contrary sign. The Königsberg observation is taken from Mr. Bessels observations for the year 1826, but it seems that there is an error of one minute in printing.

The following are the elements which $I$ have obtained from Delambre's Tables of the Sun, and Damoiseau's Tables of 1824 for the Moon. In adepting the Tables of Damoiseau, I have reduced the results from the decimal, to the sexagesimal division of the circle.

True time of ecliptic conjunction at Paris. $d \mathrm{t} m$

Mean time, Nor. . . . . . 28233444,89

Equation of mean to apparent time, at con-

junction . . . . . . . . . . + 1131,76

True time of ecliptic conjunction. Apparent

time. • . • • . . • . • 28234616,65
Longitude of the Sun and Moon at Conjunction. . . . . . . . $246^{\circ} 46^{\prime} 19^{\prime \prime} 84$ Apparent obliquity of the Ecliptic. . . 232736,86 Sun's right ascension. . . . . . . 2445538,92

— declination, north. . . . . . . 212734,17 hourly motion in Longitude . .

232,19

241,05

1615,15 Semidiameter . . . . . . horizontal parallax . . . . . 8,93 0,875

Hourly decrease of the equation of time Moon's Latitude, north increasing . . . equatorial horizontal parallax. . horizontal semidiameter. . . hourly motion in long., first order hourly motion in latit., first order ecc. order

$$
0,875
$$

11229,55

1123,84 1643,85 $38 \quad 8,447$ 0,064 325,904 0,277

George Innes. 